bioRxiv preprint doi: https://doi.org/10.1101/2020.04.06.027847; this version posted April 15, 2020. The copyright holder for this preprint (which was not certified by peer review) is the author/funder. All rights reserved. No reuse allowed without permission.

\title{
Yeast FIT2 homolog is necessary to maintain cellular proteostasis by regulating lipid homeostasis
}

\author{
Peter Jr. SHYU ${ }^{1}$, Wei Sheng YAP ${ }^{1}$, Maria Laura GASPAR ${ }^{2}$, Stephen A. JESCH ${ }^{2}$, Charlie \\ MARVALIM ${ }^{1}$, William A. PRINZ ${ }^{3}$, Susan A. HENRY², Guillaume THIBAULT1,4*
}

From the ${ }^{1}$ School of Biological Sciences Nanyang Technological University, Singapore, 637551; 2Department of Molecular Biology and Genetics, Cornell University, Ithaca, NY 14853, USA; ${ }^{3}$ Laboratory of Cell and Molecular Biology, National Institute of Diabetes and Digestive and Kidney Diseases, NIH, Bethesda, MD 20892, USA; "Institute of Molecular and Cell Biology, A*STAR, Singapore, 138673

\section{Running title: SCS3 regulates cellular proteostasis and lipid homeostasis}

*To whom correspondence should be addressed: Guillaume Thibault: School of Biological Sciences Nanyang Technological University, Singapore, 637551; thibault@ntu.edu.sg; Tel: +65 65921787.

Keywords: endoplasmic reticulum (ER), ER-associated degradation, ER quality control, endoplasmic reticulum stress (ER stress), lipid droplet, proteostasis, phospholipid metabolism, Scs3, triacylglycerol, unfolded protein response (UPR)

\begin{abstract}
Lipid droplets (LDs) have long been regarded as inert cytoplasmic organelles with the primary function of housing excess intracellular lipids. More recently, LDs have been strongly implicated in conditions of lipid and protein dysregulation. The fat storage inducing transmembrane (FIT) family of proteins comprises of evolutionarily conserved endoplasmic reticulum (ER)-resident proteins that have been reported to induce LD formation. Here, we establish a model system to study the role of S. cerevisiae FIT homologues (ScFIT), SCS3 and YFT2, in proteostasis and stress response pathways. While LD biogenesis and basal ER stress-induced unfolded protein response (UPR) remain unaltered in ScFIT mutants, SCS3 was found to be essential for proper stress-induced UPR activation and for viability in the absence of the sole yeast UPR transducer IRE1. Devoid of a functional UPR, $\operatorname{scs} 3 \Delta$ mutants exhibited accumulation of triacylglycerol within the ER along with aberrant LD morphology, suggesting a UPR-dependent compensatory mechanism for LD maturation. Additionally, SCS3 was necessary to maintain phospholipid homeostasis. Strikingly, the absence of the ScFIT proteins results in the downregulation of the closely-related Heat Shock Response (HSR) pathway. In line with this observation, global protein ubiquitination and the turnover of both ER and cytoplasmic misfolded proteins is impaired in ScFITA cells, while a screen for interacting partners of Scs3 identifies components of the proteostatic machinery as putative targets. Taken together, these suggest that ScFIT proteins may
\end{abstract}

modulate proteostasis and stress response pathways with lipid metabolism at the interface between the two cellular processes.

Lipid droplets (LDs) have long been regarded as inert cytoplasmic organelles with the primary function of housing excess intracellular lipids. LDs arise from the endoplasmic reticulum (ER) and contain a core of non-polar lipids triacylglycerol (TG) and steryl ester (SE) surrounded by a phospholipid monolayer, with phosphatidylcholine (PC) as the major component (1). More recently, LDs have been strongly implicated in conditions of lipid and protein dysregulation. These conditions are major contributors to the pathophysiology of metabolic diseases and concomitantly activate cellular stress response pathways, namely the unfolded protein response (UPR) and heat shock response (HSR). Increased LD biogenesis has been extensively observed in cells under stress conditions. Introduction of oxidative stressors or the attenuation of antioxidant capacities of cells result in the formation of LDs (2-4). While the extent of UPR activation and the resulting transcriptional profile differs between proteotoxic and lipid stress, a similar increase in lipogenic markers and concomitant LD formation is observed (510). It remains to be determined whether LDs contribute to stress induction or if this is reflective of the adaptive role of LDs to mitigate the otherwise deleterious effects of stress. However, all these undoubtedly highlight the complex integration of LDs in stress response pathways. In addition to this, the UPR regulates 
bioRxiv preprint doi: https://doi.org/10.1101/2020.04.06.027847; this version posted April 15, 2020. The copyright holder for this preprint (which was not certified by peer review) is the author/funder. All rights reserved. No reuse allowed without permission.

metabolic pathways to a certain extent under normal physiological conditions (11), and similarly orchestrates the complex transcriptional metabolic reprogramming under ER stress induction (7).

The fat storage-inducing transmembrane (FIT) family of proteins constitutes a group of evolutionarily conserved proteins eponymously named for their role in lipid metabolism and LD formation (12). In mammals, FIT proteins exhibit differential expression patterns, with FIT1 being expressed primarily in cardiac and skeletal muscle tissue, and FIT2 being more ubiquitously expressed. FIT proteins (FIT1/FIT2) are ER-resident proteins with a total of six transmembrane domains and with both $\mathrm{N}$ - and C- termini facing the cytosol $(12,13)$. S. cerevisiae FIT2 homologs (ScFIT), SCS3 and YFT2, are predicted to share the same membrane topology. The pioneer study on the FIT proteins has identified its profound effect on the formation and accumulation of LDs both in vitro and in vivo (12). Transient overexpression of FIT2 was sufficient to drive the formation of LDs, a process that was later hypothesized to be mediated by the capacity of FIT2 to directly bind and partition TG from the ER into storage in LDs in vitro (13). Transgenic expression of the mammalian FIT2 gene in the budding yeast $S$. cerevisiae (14) and in the plant models Arabidopsis thaliana and Nicotiana tabacum (15) induced the formation of cytoplasmic LDs. Similarly, transient expression of the ScFIT genes in mammalian cells in vitro led to the increased formation of LDs (14). A gain-of-function FIT2 mutant was identified with a 3-amino acid mutation within its fourth transmembrane domain, which interestingly houses the most highly conserved amino acid residues from yeast to humans (16). Conversely, it was found that the deletion of FIT2 greatly compromised LD formation in the model organisms, Danio rerio and Caenorhabditis elegans, as well as in the pathogenic yeast Candida parapsilosis $(12,17,18)$. Similar findings were observed in FIT2-ablated human cells cultured in vitro (19). All these reports further reinforced the initial hypothesis of the FIT proteins directly functioning in LD biogenesis.

In contrast, $S$. cerevisiae deletion mutants for either or both ScFIT genes retain their capacity to form LDs, with size and number comparable to WT $(14,19)$. Upon closer investigation, it was found that LDs fail to completely bud off from the ER in the absence of the ScFIT proteins (17), presumably through alterations in ER membrane lipid properties (20). These findings have since then led to the investigation of alternative functions of the FIT class of proteins. SCS3 was initially reported to have a putative role in the regulation of phospholipids (21), a function that was largely unexplored until a large-scale genetic screen reported on the strong interactions between the ScFITs and genes involved in phospholipid biosynthesis, including DGK1 and PSD1 (14). In-depth analysis of the ScFIT protein sequences have since then revealed the presence of the catalytic site of a lipid phosphatase (22). This finding was further corroborated by a separate study that reported the same observation on the mammalian FIT2 sequence (19). In vitro analyses have identified the capacity of mammalian FIT2 to hydrolyze phosphates from phosphatidic acid (PA) and lyso-PA to yield diacylglycerol (DAG) and monoacylglycerol (MAG), respectively. On the other hand, substrates for the lipid phosphatase activity of the ScFIT proteins have yet to be determined. This conserved catalytic function has been associated with the aberrant ER whorling phenotype observed in cells devoid of the FIT proteins $(19,22)$.

Conjointly, several different perspectives now exist on the function of the ScFIT proteins. However, definitive evidence for the function of FIT proteins either in binding and partitioning NLs or influencing NL and phospholipid metabolism in the complex in vivo environment remains scarce. Moreover, how any of these functions are relevant in the context of cellular function and broader physiological processes has mostly been left uncharacterized.

In this study, we investigated the role of SCS3, identified as one of the downstream UPR target genes. As the UPR transducer Ire1 is essential for viability in the absence of SCS3, we generated temperature sensitive allele scs3-1 to reveal its role without the masking effect of the UPR program. We demonstrated that dysfunctional SCS3 leads to the accumulation of TG at the ER, to a shift in phospholipids distribution, and the biogenesis of aberrant LD morphology. Furthermore, we identified the interactome of ScFITs of which Scs3 interacts with components of the proteostatic machinery. Next, we demonstrated that ScFIT mutants impaired the clearance of ER-associated degradation (ERAD) client proteins, which was exacerbated by lipid imbalance. Together, our data support a model where ScFITs modulate proteostasis and stress response pathways with lipid metabolism at the interface between the two cellular processes. 


\section{Results \\ Scs 3 is essential for viability in the absence of UPR transducer Ire1}

Synthetic genetic array (SGA) analyses revealed the synthetic lethality between SCS3 and IRE1, which encodes for the sole UPR transducer in yeast (14). Additionally, the mutant $\operatorname{scs} 3 \Delta$ strain has been reported to activate the UPR (23), while SCS3 was conversely shown to be transcriptionally upregulated upon UPR activation resulting from either proteotoxic stress or lipid bilayer stress (LBS) $(7,10,24)$. As previously reported $(17,19,22)$, Scs3 and Yft2 proteins localize to the ER (Fig. S1A). Herewith, we sought to further understand the role of SCS3 within the UPR program. First, we monitored the UPR activation using the UPR element (UPRE)-LacZ reporter assay (25). Unexpectedly, no significant UPR activation was observed in scs $3 \Delta$ mutants, contradicting a previous report (23) while being consistent with other findings (14) (Fig. 1A). Similarly, there was no significant UPR activation in yft2 $\Delta$ nor in ScFITA. All mutant strains are fit to mount an UPR response upon treatment with ER stressinducing agent tunicamycin $(\mathrm{Tm})$ although the level of activation was significant lower in $s c s 3 \Delta$ and ScFITA. Similarly, the heat shock response (HSR), a cytosolic proteotoxic stress compensatory pathway, was dampened in ScFITA upon heat stress (Fig. S1B and S1C). To complement the UPR assay, we asked if SCS3 and YFT2 genes are upregulated in a UPR dependent manner. SCS3 was significantly upregulated while YFT2 was mildly upregulated in WT cells treated with Tm (Fig. 1B). As depleting the media of inositol induces the UPR by LBS $(10,26,27)$, we measured the mRNA levels of both genes upon inositol depletion (- ino) and only SCS3 exhibited a mild but significant upregulation. To further assess the role of SCS3 during ER stress, we carried out a growth assay. The spotting assay revealed that the lack of SCS3 exhibits growth defect in the presence of $\mathrm{Tm}$ which can be rescued with the overexpression (OE) of SCS3 (Fig. 1C). Together, these results demonstrate that SCS3 is essential during ER stress conditions.

As lipogenic pathways constitute one of the major effectors of the UPR (28) and that LDs are associated with stress conditions, the putative function of Scs3 in LD formation may then provide a rationale for its UPR-dependent transcriptional upregulation. We further hypothesized that the inability of $s c s 3 \Delta$ mutants to mount a maximal UPR under proteotoxic stress conditions may translate to the impairment of LD formation as part of the stress response. We made use of fluorescent BODIPY $493 / 503$ to stain LDs in $\operatorname{scs} 3 \Delta$ mutants challenged with $\mathrm{Tm}$-induced stress to evaluate gross changes in LD formation. The mutant cells are still able to form LDs to the same extent as that of WT cells under unstressed and ER stressed conditions (Fig. 1D and S2). Next, we sought to determine the extent by which the UPR compensates for the absence of SCS3, particularly in respect to LD formation. However, a scs3 $3 \Delta$ ire $1 \Delta$ mutant is synthetically lethal, thus rendering conventional deletion strategies unusable in titrating the phenotypic effects of the UPR upon the loss of SCS3. To address this, we generated a conditional temperature sensitive scs3 allele (scs3-1) that is functional at a permissive temperature of $25^{\circ} \mathrm{C}$ but not at the restrictive temperature of $37^{\circ} \mathrm{C}$ in the absence of IRE1 (Fig. 1E and S3), using a screening strategy that we previously reported $(7,29,30)$. As IRE1 is not essential in the absence of YFT2, a temperature sensitive allele of $y f t 2$ was not generated (Fig. S3B). This provides strong support for the interdependence between IRE1 and SCS3 and that one is required for viability in the absence of the other, consistent with SGA results showing synthetic lethality between these two genes (14).

\section{Scs3 is essential to maintain lipid} homeostasis at the ER and LD morphology In $\operatorname{scs} 3 \Delta$ and $y f t 2 \Delta$ mutants, LDs remain irreversibly tethered to the ER and are wrapped by a membrane. Jacquier et al. suggest that, in yeast, LDs always remain connected to the ER (31). We hypothesized that while these knockout strains are fully capable of forming LDs (Fig. 1D), it is possible that these LDs remain tightly associated with the ER, resulting in the disruption of ER lipid homeostasis, as previously reported $(17,20)$. Temperature sensitive allele strains were grown to early logphase at $25^{\circ} \mathrm{C}$ followed by a temperature shift of $2 \mathrm{~h}$ at $37^{\circ} \mathrm{C}$. To assess the levels of neutral lipids in the ER, we extracted total lipids from microsomes of the cells and triacylglycerols (TG) was separated by thin layer chromatography (TLC) and quantified by gas chromatography with flame ionization detector (GC-FID) (Fig. 2A). A significant increase in TGs within the microsomal fractions of scs3-1 strain was only observed in the absence of IRE1 at the restrictive temperature of $37^{\circ} \mathrm{C}$, thereby suggesting that the presence of the UPR exerts a suppressive effect for this phenotype. As LDs were wrapped with ER membranes in $s c s 3 \Delta$ and $y f t 2 \Delta$ yeast mutants using inducible TG synthesis system (17), we 
asked if the UPR plays a role in the budding and morphology of LDs. Transmission electron microscopy (TEM) was performed on scs3-1 and ire $1 \Delta s c s 3-1$ cells following temperature shift. Strikingly, we observed irregular LD morphology in scs3-1 and ire $1 \Delta s c s 3-1$ cells (Fig. 2B and S4). The abnormally elongated LDs are embedded in ER. Additionally, LDs were smaller in ire $1 \Delta s c s 3-1$ cells compared to scs3-1 cells at $37^{\circ} \mathrm{C}$. Taken together, our findings suggest that Scs3 is necessary to maintain neutral lipid homeostasis at the ER and that the UPR plays an important role to regulate TAG levels.

The transcription of a subset of genes encoding phospholipid biosynthesis enzymes are inhibited in the presence of phospholipid precursors inositol and choline (32-34). Additionally, the absence of inositol in yeast growth media induces the UPR $(10,26,27)$. Therefore, we asked if Scs3 plays a role modulating phospholipid homeostasis in the absence of inositol and choline. We performed lipid analysis of cells grown in media containing inositol and choline to mid-logarithmic phase before being shifted to a $3 \mathrm{~h}$ incubation in media lacking inositol and choline. Unexpectedly, $\operatorname{scs} 3 \Delta$ mutant cells contained 4 times the phosphatidylcholine (PC) levels of WT cells (Fig. 2C). PC levels of scs3 $\Delta$ cells were significantly decreased in pct1 $\Delta$ background mutant suggesting that PC is mostly synthesized through the Kennedy pathway in the absence of SCS3. Pct1 is a cholinephosphate cytidylyltransferase enzyme. Phosphatidylserine (PS) and phosphatidylethanolamine (PE) were also found to be two times more abundant in $\operatorname{scs} 3 \Delta$ mutant compared to WT cells while there was no significant difference in phosphatidylinositol (PI) levels. Next, we tested if supplementing the media with inositol and choline will restore phospholipid levels in scs $3 \Delta$ mutant. In contrast to the absence of both lipid precursors, we observed a decrease of about 4 times of $P C$ in scs3 3 mutant compared to WT cells (Fig. 2D). There was also a significant decrease of $\mathrm{PI}$ in $\operatorname{scs} 3 \Delta$ mutant. To further understand the role of Scs3 in modulating phospholipids, we measured the levels of PC and PI over the course of $3 \mathrm{~h}$ of cells grown in media depleted of inositol followed by a $0.5 \mathrm{~h}$ recovery (+ ino) period. In the presence of choline, $s c s 3 \Delta$ failed to increase the synthesis of PI upon the reintroduction of inositol while PI level increased rapidly in WT (Fig. 2E). On the other hand, there was a constant decrease of PC levels in scs3 $\Delta$ while PC levels continually increased in WT during the $3 \mathrm{~h}$ of inositol depletion. Together, these data reveal that $\operatorname{Scs} 3$ is essential to maintain phospholipid homeostasis. We speculate that the decrease of $\mathrm{PI}$ in $\operatorname{scs} 3 \Delta$ cells might alter the composition of complex sphingolipids (35) which in turn would induce the UPR (36).

\section{Scs3 interacts with components of the proteostatic machinery}

To gain further insight into the physiological relevance of ScFIT proteins within the cell, we employed the split-ubiquitin based membrane yeast two hybrid (MYTH) screen (37). The reporter moiety was fused to the $\mathrm{N}$-terminal or the C-terminal cytosolic domains of both Scs3 and Yft2. The four bait constructs were validated, and screening conditions for each were optimised with 3'-amino-1,2,4,-triazole (3'AT) supplementation in the selection media to reduce the occurrence of false positives. Following this, 1,344 colonies were collectively screened for all reporter strains. From these, 664 colonies were positive for bait-prey interaction as manifested by blue colony growth on $\quad 5$-bromo-4-chloro-3-indolyl- $\beta$-Dgalactopyranoside (X-gal) supplemented selective media and are designated as putative interactors (Fig. S5). These were further validated for specificity towards the bait protein of interest in comparison to the single-pass human cluster of differentiation 4 (CD4) receptor protein, which served as a negative control. From these, 189 showed specific interactions with the ScFIT proteins. Following sequence analysis, 88 unique protein interactors were identified. Considering the overlap in protein interactors, the MYTH screen identified a total of 73 genuine and unique interactors for the ScFIT proteins, which were further categorized according to cellular functions (Fig. 3). Moreover, our screen results show that more than half of the identified Yft2 protein interactors are shared with that of Scs3, thereby supporting a certain degree of functional redundancy between the two.

Surprisingly, only few of the ScFIT protein interactors identified with the screen are directly involved in lipid metabolism, suggesting that ScFIT proteins may not function extensively in that cellular process. It could also be noted that while the encoded proteins of genes that SCFIT had high degrees of genetic interactions with, such as ICE2, SEY1 and UBX2 (14,38), were not identified with the MYTH screen, this does not exclude the presence of a physical interaction. However, this alternatively suggests that they function in parallel but independently in the same cellular process, and 
that the loss of both is detrimental to cell viability.

Interestingly, several proteins that function in proteostasis and the ubiquitin-proteasome system (UPS) have been found to interact with Scs3 (Fig. 3 and S5). Of note are the J-protein chaperone Zuo1 and the Hsp70 chaperone Ssb2, both of which have been reported to function in protein quality control (39-41). Doa10 is one of the key E3 ubiquitin ligases in yeast, and is involved in ER-associated degradation (ERAD) of proteins (42-44). Lastly, Pup1 is a subunit of the yeast 20S proteasome core $(45,46)$. Taken together, these suggest that Scs3 may function to a certain extent in protein quality control pathways, specifically in the UPS.

\section{The clearance of ERAD client proteins is impaired in ScFIT mutants}

As the accumulation of misfolded proteins and the ensuing proteotoxicity is closely related to the ability of cells to efficiently process client proteins, we hypothesized that the sensitivity to Tm exhibited by scs $3 \Delta$ and ScFITA mutants may be the result of impaired protein degradation pathways, as in the case of $u b \times 2 \Delta$ mutants having impaired turnover of both misfolded ER and cytosolic substrates (47). Following the identification of UPS machinery components as protein interactors of Scs3, we asked if ScFIT plays a role in protein ubiquitination. We overexpressed myc-tagged ubiquitin (Ub-Myc) through and inducible CUP1 promoter and quantified the extent of total protein ubiquitination in cells by immunoblotting. The amount of ubiquitinated proteins in SCFITS mutants was significantly reduced by approximately $38 \%$ relative to that of WT cells, with a less pronounced reduction of $18 \%$ in $\operatorname{scs} 3 \Delta$ single mutants (Fig. S6). Since the stabilization of protein substrates was accompanied by a decrease, rather than an increase in high molecular weight ubiquitin antibody-reactive proteins, the inefficient turnover of the said substrates is likely due to a failure to mark them correctly for degradation and not because of efficient clearance in the proteasome.

To investigate if the global decrease of ubiquitinated proteins correlates with protein stability, we measured the turnover of known ERAD substrates in mutants of ScFIT by the cycloheximide chase assay. We expressed HAtagged Sbh2, Yeh1, and Pgc1 in ScFITA mutant. These native proteins are dependent on Doa10-mediated ERAD for normal degradation $(42,48)$. The turnover rates of Sbh2 and Yeh1 in ScFITA mutants was similar to WT (Fig. S7A and B). In contrast, the degradation of Pgc1 was significantly accelerated in ScFITA mutants (Fig. S7C). Along with the identification of Pgc1 as a Doa10-dependent ERAD substrate, its proper localization dynamics between the ER and LD membranes was found to be critical in determining its stability (48). Doa10 reportedly recognizes ER-localised Pgc1 through its hairpin loop, which then serves as a degron that concentrates Pgc1 on the surface of LDs. As LDs fail to properly mature in the absence of the ScFIT proteins (Fig. 2B), the lateral diffusion of the pool of Pgc1 proteins to the ER may be increased in ScFITA mutants, resulting in continual degradation by Doa10 (49). We hypothesized that native proteins in their proper conformation may not illicit a proteotoxic effect on ScFITA cells, and that an otherwise compromised protein degradation pathway in this mutant could remain fully capable of clearing these endogenous proteins.

As misfolded model substrate, we monitored the protein levels of epitope-tagged versions of misfolded CPY (CPY*-HA) (Fig. 4A). A small but significant delay in the degradation of $C P Y^{*}$ was only observed in SCFITA mutants but not in $\operatorname{scs} 3 \Delta$ nor $y f t 2 \Delta$. Next, we measured the degradation rates of the engineered misfolded variant of the Pep4 vacuolar protease (ngPrA* $\Delta 295-331-\mathrm{HA})$ (50) (Fig. 4B). In contrast to $\mathrm{CPY}^{*}$, SCFITS exhibited a strong defect in the degradation of ngPrA* $\Delta 295-331$ HA in comparisons to WT and single mutants. Both are luminal soluble substrates which are degraded in a Hrd1-dependent manner $(29,50)$. To further assess if the global decrease of ubiquitinated proteins is associated to ScFIT, we monitored the degradation of San1dependent cytosolic protein quality control (CytoQC) substrates $\triangle 2$ GFP-HA and ssPrA-HA (51). Consistent with our results using misfolded ERAD substrates, we found that ScFITA mutants are unable to efficiently clear away both cytosolic substrates compared to WT cells or either of the single mutants (Fig. S8). As neither of the single deletion mutants resulted in a stabilization of the ERAD substrates, the two may share a redundant yet poorly understood function. YFT2 is reported to have been the result of the segmental duplication of SCS3 (14). This is supported by the more pronounced growth sensitivity to $\mathrm{Tm}$ in the double ScFITA mutant in comparison to a mild defect in $\operatorname{scs} 3 \Delta$ cells (Fig. 1C). This, along with the broader range of Scs3 protein interactors (Fig. 3), also suggests of an asymmetric redundancy wherein YFT2 only partially compensates for the absence of SCS3 
functionality in the ERAD pathway, which ultimately results in less apparent phenotypic defects in $y f t 2 \Delta$ mutants.

To further investigate the role of lipid homeostasis and protein quality control, we monitored the degradation of CPY* in ScFITA mutant strains supplemented with inositol (+ino, -cho), choline (-ino, +cho), or both (+ino, +cho). There was a significant defect in the degradation of $\mathrm{CPY}^{*}$ in $\operatorname{scs} 3 \Delta$ and $y \mathrm{ft} 2 \Delta$ supplemented with choline compared to inositol (Fig. 4C and D). Similarly, the degradation of CPY* was slower in scs3A and ScFITA compared to WT in the presence of choline. Next, to validate the role of Scs3 in modulating ERAD, we monitored the degradation of ngPrA ${ }^{*} \triangle 295-331-H A$ in ScFITA overexpressing (OE) SCS3. In ScFITA, ngPrA* 2 295-331-HA was degraded at a significantly slower rate compared to WT cells (Fig. 5A). On the other hand, the degradation of $\operatorname{ngrA}^{*} \triangle 295-331-\mathrm{HA}$ was similar in SCFITA OE SCS3 to WT and SCFITA strains, suggesting that SCS3 is sufficient to rescue the ERAD defect. In the presence of choline $(-$ ino, + cho), the degradation of $\mathrm{ngPrA}{ }^{*} \Delta 295-331-\mathrm{HA}$ was decelerated in the three strains (Fig. 5B). Interestingly, OE SCS3 in ScFITA cells supplemented with choline (- ino, + cho) significantly accelerated the degradation of CPY*-HA compared to WT and ScFITS (Fig. 5C). As lipid homeostasis correlates with ERAD fitness $(7,52)$, these finding reinforce the notion that ScFIT is essential to regulate lipid levels at the ER and that it contributes to ER proteostasis.

\section{Discussion}

Lipid droplets have been increasingly implicated in disease pathophysiology. Despite this, our understanding of its involvement is obscure at best as LD biology is still in its infancy, and more mechanistic insight into LD formation is warranted to grasp its relevance and importance in physiological processes. From the simple budding yeast, several proteins have been identified to influence LD generation (53-55). Among these, the FIT2 class of proteins has similarly gained much interest in recent years, but its initial putative role in LD formation as a lipid-binding protein has recently been contested in favor of a broader function in membrane homeostasis. However seemingly disparate, the identification of lipid phosphatase activity in FIT2 may not be mutually exclusive with previous reports of its involvement in LD biogenesis. Given this, the molecular mechanism by which these two processes are linked is poorly understood, as well as its potential implication for the normal functioning of cells outside the context of LD formation. In this study, we report on the involvement of the yeast FIT homologs (ScFIT) not only in the maintenance of ER membrane homeostasis, but also in coordinating the cellular stress response pathway, namely the UPR, and its consequent impact on protein quality control (Fig. 6).

The complexity of lipid metabolic pathways is underscored by the highly interconnected conversion of intermediates as well as the various organelles and proteins that mediate these processes $(56,57)$. In addition to this, perturbation of the lipid metabolic pathways results in the extensive reprogramming of the bioenergetic network $(58,59)$. Similarly, cellular insults also alter the lipidomic landscape of cells, suggestive of the buffering capacity of lipid pathways against stress conditions. Proteotoxic or lipid bilayer stress (LBS) both activate the UPR and similarly culminate in the formation of LDs. Interestingly, none of the previously reported major protein effectors of LD biogenesis were identified as UPR targets. Moreover, apart from the SE biosynthetic $A R E 2$, no other NL synthesis players are upregulated under conditions of ER stress $(7,24)$. Given the recent report of Scs3 as a lipid phosphatase, its consequent upregulation under the UPR program could be part of the effort to orchestrate membrane remodeling.

It was reported that LDs in ScFITA cells remain embedded in the ER due to the enrichment of DG, a lipid species with negative membrane curvature, as is the case with the accumulation of $\mathrm{PE}$ in a mutant of $\mathrm{CHO}$, a methyltransferase for PC synthesis (20). Interestingly, the addition of either of the positive curvature phospholipids, lyso-PC or lyso-PA, rescued the aberrant LD budding of SCFITA cells. The failure of the UPR to restore proper LD maturation in cho2 $\Delta$ cells may result from the markedly reduced capacity to synthesize PC, which exhibits a neutral curvature and is an intermediate to lyso-PC (60). While cho2 $\Delta$ cells indeed accumulated high levels of PE, DG levels are dramatically reduced (7). This taken together with the observation that the gain-of-function DGbinding FIT mutant failed to rescue the aberrant ER membrane whorling in scs3 3 cells (19) strongly suggest that defects in ER membrane properties that led to impaired LD maturation may be independent from DG. In contrast, we observed an accumulation of TG at the ER together with irregularly shaped LDs that were detached to the ER in scs3-1 (Fig. 2B and S4), reinforcing the role of Scs3 in lipid homeostasis. 
While the catalytic activity of mammalian FIT2 on PA and lyso-PA was not identified in ScFIT proteins $(19,22)$, this does not exclude the possibility that the latter may instead act on other membrane lipid species in vivo. Mammalian FIT2 is proposed to be a lipid phosphate phosphatase enzyme based on in vitro evidence (19). As SCS3 is essential for viability in the absence of a functional UPR (Fig. 1 ), it can then be hypothesized that Scs3 regulates ER membrane lipid composition, presumably through the conversion of DAG from PA (19), to maintain proper ER function including LD maturation. Taken together, these findings highlight the important role of Scs3 in maintaining ER lipid homeostasis. A unifying model on the role of Scs3 in vivo by either acting as an enzyme that catalyzes DAG synthesis, by regulating other enzymes, or by regulating lipid metabolism through other ways should emerge in future studies.

The loss of both FIT homologs in ScFITA mutants led to the unexpected stabilization of misfolded proteins in both within the ER and in the cytoplasm (Fig. 4, 5, and S8) which correlate with a global decrease in protein ubiquitination (Fig. S7). The maintenance of ER membrane integrity and lipid homeostasis are critical in supporting organellar function. Loss of ICE2 exhibits altered ER membrane dynamics including defects in mother-daughter cell ER membrane inheritance and ER-plasma membrane tethering $(61,62)$. This ER membrane perturbation further impaired cellular functions such as phospholipid regulation and protein degradation (38,63-65). Similarly, mutants of the phospholipase Lpl1, which catalyzes the turnover of phospholipids, also exhibited ERAD defects $(66,67)$. The general disruption of lipid metabolism by attenuating FA synthesis in turn caused defects in processing of ERAD client proteins in mammalian systems (68), which may also be in part due to its indirect effects on membrane lipid composition. Conversely, defective protein turnover also exerted a direct effect on membrane composition. The deletion of the ERAD component UBX2 led to severe changes in ER membrane morphology due to dysregulation of Mga2 processing and the subsequent expression of its transcriptional target OLE1, a key regulator of membrane lipid saturation (69). Sterol content within membranes are also under tight control by protein quality control pathways, as the key enzymes Hmg2 and Erg1 are regulated in an ERAD-dependent mechanism (70,71). Intriguingly, these mutants with aberrant membranes exhibited impaired LD formation in addition to curtailed protein turnover $(63,67,72)$.

In a previous study, we have shown that the singular UPR transducer Ire1 in yeast is strongly activated with genetic alterations of ER membrane composition (7). We also identified a LBS sensing switch located at the interface of the amphipathic and transmembrane helices (10) while key residues within the amphipathic helix of Ire1 were reported to be important to sense LBS- and proteotoxic-induced ER stress (27). As ER membrane morphology is compromised in ScFIT mutants, it could be hypothesized that proper Ire1 and UPR activation may not proceed as efficiently, which in turn affects ERAD function. In line with this, several studies lend support for the modulation of LDs by protein quality control pathways including ERAD. The ubi4A mutant was reported to exhibit less LD accumulation compared to that of WT cells under stress (73). While the rationale for this increase in LD remains enigmatic, it suggests that LD formation may in part be regulated by ubiquitination processes. This agrees with previous studies that detailed on the dependence of the NL biosynthetic enzyme Dga1 and SE lipase Yeh1 on Doa10 for their endogenous turnover (48), and that recruitment of the mammalian ERAD factor UBXD8 onto the LD surface regulates LD growth by modulating lipolysis (74). Apart from LDs, ERAD pathways also regulate the ER membrane composition and phospholipid turnover. The Cdc48 ATPase mediates the processing of the ER membrane sensors Mga2 and Spt24, to yield the cognate transcription factor for OLE1 regulation $(69,75,76)$, and the degradation of phosphorylation-inactive Pah1 is impaired in proteasome and ubiquitination mutants $(77,78)$. Taken together, these greatly emphasizes the interdependence of membrane homeostasis and protein quality control pathways.

In this study, we build on the current hypothesis on the role of ScFIT proteins in LD formation and membrane homeostasis, and further provide support for its functioning in cell stress response pathways to exert effects on these two processes. (Fig. 6).

\section{Experimental procedures Statistics}

Error bars indicate standard error of the mean (SEM), calculated from at least three biological replicates, unless otherwise indicated. $P$ values were calculated using one-way ANOVA with 
Tukey's post hoc test, unless otherwise indicated and reported as $P$ values with 4 significant digits in the figures. All statistical tests were performed using GraphPad Prism 7 software.

\section{Strains and antibodies}

Saccharomyces cerevisiae strains used in this study are listed in Table S1. Strains were generated using standard cloning protocols. Anti-HA mouse monoclonal antibody HA.11 (Covance), anti-tubulin mouse monoclonal antibody 12G10 (DHSB), and anti-myc mouse monoclonal antibody (Invitrogen), were commercially purchased. Secondary antibodies goat anti-mouse IgG-DyLight 488 (Thermo Fisher, Waltham, MA), goat anti-mouse IgGIRDye 800 (LI-COR Biosciences) and goat antirabbit IgG-IRDye 680 (LI-COR Biosciences) were commercially purchased.

\section{Plasmid used in this study}

Plasmids and oligonucleotide primers used in this study are detailed in Table S2 and S3, respectively. Plasmids constructs were generated through either conventional restriction enzyme cloning methods or Gibson Assembly (New England Biolabs). The mutant scs3 library was generated by low-fidelity PCR using primers PS1-PS2 to amplify the promoter, coding sequence, and terminator regions of the SCS3 from the genomic DNA of wild type (WT) cells. The PCR product was then digested with the enzymes EcoRl and Xbal before ligation into pGT0004. Plasmid pGT0364 was obtained through a colony sectoring screen detailed in the Genetic screen for temperature sensitive alleles section below. Plasmid pGT0286 encoding for WT SCS3 was similarly generated using conventional PCR amplification. To generate reporter constructs for the membrane yeast two hybrid screen, the coding sequences of SCS3 and YFT2 were amplified from WT yeast DNA using primer pairs PS39-PS40 and PS159-PS160, respectively. These were then inserted via Gibson Assembly into vector backbones generated through PCR from pGT0317 using primer pairs PS39-PS40 and PS157-PS158, respectively, to generate pGT0374 and pGT0427. Plasmids pGT0426 and pGT0428 were generated through Gibson Assembly by amplifying the coding sequence of SCS3 and YFT2 terminating immediately before the stop codon using WT yeast DNA with primer pairs PS107-PS108 and PS101-PS102, respectively. These were then cloned into PCRamplified vector backbones using pGT0318 as template with primer pairs PS105-PS106 and PS36-PS99, respectively.

\section{Spotting growth assay}

Strains were grown to saturation in appropriate selective medium overnight at $30^{\circ} \mathrm{C}$. Cultures were diluted to $0.2 \mathrm{OD}_{600} / \mathrm{ml}$ and serially diluted fivefold for a total of four dilutions. The cell suspensions were then spotted onto appropriate agar plates and incubated at indicated temperatures until the appearance of colonies.

\section{$\beta$-galactosidase reporter assay}

The $\beta$-galactosidase reporter assay was carried out as previously described (29). Typically, cells were grown to early log phase, and tunicamycin (Tm) was added to growth cultures when specified at a concentration of $2.5 \mu \mathrm{g} / \mathrm{ml}$ to cells $1 \mathrm{~h}$ prior to harvest or a temperature shift to $37^{\circ} \mathrm{C}$, for the induction of the UPR and HSR, respectively. Four $\mathrm{OD}_{600}$ units of cells were pelleted, washed and resuspended in $75 \mu \mathrm{l}$ LacZ buffer (125 mM sodium phosphate $\mathrm{pH} 7$, $10 \mathrm{mM} \mathrm{KCl}, 1 \mathrm{mM} \mathrm{MgSO}_{4}, 50 \mathrm{mM} \beta$ mercaptoethanol). An aliquot of $25 \mu \mathrm{l}$ was transferred into $975 \mu \mathrm{l} \mathrm{ddH}_{2} \mathrm{O}$ and the absorbance was measured at $600 \mathrm{~nm}$. To the remaining suspension, $50 \mu \mathrm{l}$ of $\mathrm{CHCl}_{3}$ and $20 \mu \mathrm{l}$ of $0.1 \%$ SDS were added and vortexed vigorously for $20 \mathrm{~s}$. The reaction was started with the addition of $700 \mu \mathrm{l}$ of $2 \mathrm{mg} / \mathrm{ml} \mathrm{2-}$ nitrophenyl- $\beta$-galactopyranoside (ONPG; Sigma) in LacZ buffer. Next, the reaction was quenched with $500 \mu \mathrm{l}$ of $1 \mathrm{M} \mathrm{Na}_{2} \mathrm{CO}_{3}$, and total reaction time was recorded. Samples were spun for $1 \mathrm{~min}$ at maximum speed. Absorbance of the resulting supernatant was measured at 420 and $550 \mathrm{~nm}$. The $\beta$-galactosidase activity was calculated using Eq. (1)

$$
\text { Miller units }=\left\{\frac{\mathrm{OD}_{420}-1.75 \times \mathrm{OD}_{550}}{\left[\mathrm{t} \times\left(\frac{\mathrm{V}_{\mathrm{A}}}{\mathrm{V}_{\mathrm{R}}}\right) \times \mathrm{OD}_{600}\right]}\right\} \times 1000
$$

\section{qPCR}

Cells were grown to an early log phase overnight at $30^{\circ} \mathrm{C}$. Tunicamycin was added to a final concentration of $2.5 \mu \mathrm{g} / \mathrm{ml}$ and incubated $1 \mathrm{~h}$ at $30^{\circ} \mathrm{C}$ or depleted of inositol for $2 \mathrm{~h}$, when indicated. Total RNA was extracted using RNeasy Mini Kit (Qiagen) following manufacture's protocol. DNase treatment in columns was carried out with RNase-free DNase (Qiagen, Venlo, Netherlands) following the manufacturer's protocol. cDNA was synthesised from $2 \mu \mathrm{g}$ of total RNA using RevertAid reverse transcriptase (Thermo Fisher, Waltham, MA) following manufacturer's protocol. SYBR Green qPCR experiments were performed following the manufacturer's protocol using a QuantStudio 6 Flex Real-time PCR system (Applied Biosystems, Waltham, MA). cDNA (30 ng) and $50 \mathrm{nM}$ of paired-primer 
mix were used for each reaction. Relative mRNA was determined with the comparative $\mathrm{Ct}$ method $(\Delta \Delta \mathrm{Ct})$ normalised to housekeeping gene $A C T 1$. Oligonucleotide primers used are listed in Table S3.

\section{Lipid droplets analysis}

Cells were grown to early log phase and $500 \mu \mathrm{L}$ of the suspension was transferred on a coated slide with $10 \mathrm{mg} / \mathrm{ml}$ Concanavalin A (SigmaAldrich, St. Louis, MO) mounted onto Attofluor cell chamber (Thermo Fisher, Waltham, MA) and imaged at RT. Tunicamycin was added to a final concentration of $2.5 \mu \mathrm{g} / \mathrm{ml}$ and incubated at $30^{\circ} \mathrm{C}$ for $1 \mathrm{~h}$, when indicated. To stain lipid droplets, cells were incubated with $0.05 \mu \mathrm{g} / \mathrm{ml}$ BODIPY 493/503 (Invitrogen) in phosphate buffered saline ( $\mathrm{pH}$ 7.4) for $10 \mathrm{~min}$ at $\mathrm{RT}$, washed and resuspended in liquid medium before transferring into the Attofluor cell chamber for viewing. Samples were imaged with a Leica DMi8 system (HCX PL APO 100x/1.4-0.70 oil immersion objective) under the control of Metamorph Ver. 7.8.10.0, or Zeiss LSM710 Microscope (100× 1.4 NA PlanApochromat oil-immersion objective) under the control of Zen (Carl Zeiss Microlmaging).

\section{Genetic screen for temperature sensitive alleles}

The genetic screen was performed as previously reported (30). A mutant library of the SCS3 open reading frame flanked by $500 \mathrm{bp}$ of its endogenous promoter and $300 \mathrm{bp}$ of its terminator was generated by low-fidelity PCR using Taq DNA polymerase in the presence of 0.05 and $0.1 \mathrm{mM} \mathrm{MnCl}$. DNA fragments were digested with $E c o R I$ and $X b a l$ and ligate into digested pRS316 to produce a plasmid library scs3* with random point mutations. The strain YGT0492 was transformed with the mutant library pRS316-scs3* and transformants were spread on selecting synthetic complete lacking uracil (SC-Ura) plates with limiting adenine (low Ade) at $6 \mu \mathrm{g} / \mathrm{ml}$. Plates were incubated at $25^{\circ} \mathrm{C}$ until colonies developed fully red pigmentation due to low Ade. Colonies with sectoring phenotype were streaked in duplicate on SCUra, low Ade, and incubated at $25^{\circ} \mathrm{C}$ and $37^{\circ} \mathrm{C}$. For the primary screen, 123 colonies were screened for positive clones which sectored at $25^{\circ} \mathrm{C}$ but remained red at $37^{\circ} \mathrm{C}$. From the positive clones, sectoring phenotype at $25^{\circ} \mathrm{C}$ were re-streaked in duplicate on SC-Ura, low Ade, and incubated at $25^{\circ} \mathrm{C}$ and $37^{\circ} \mathrm{C}$ to eliminate false positive. Positive clones were isolated without the plasmid pDN388. Plasmids were extracted from the clones and subjected to DNA sequencing analysis to identify the mutation present in $\operatorname{scs} 3$ temperature sensitive (ts) alleles. The plasmid pGT0364, containing scs3 ts allele (scs3-1) encodes for Scs3 with the following mutated residues D277G and I328V. The plasmid pGT0364 was transformed in strain YGT0492.

\section{Lipid extraction and fatty acid analysis}

Cells were grown to early log phase at $25^{\circ} \mathrm{C}$ followed by a $2 \mathrm{~h}$ incubation at $37^{\circ} \mathrm{C}$. For whole cell lipid extraction, $10 \mathrm{OD}_{600}$ of cells was washed, pelleted in a glass vial, and lyophilised using Virtis Freezer Dryer under vacuum. All subsequent steps were carried out at $4^{\circ} \mathrm{C}$. For lipid extraction of microsomes, $30 \mathrm{OD}_{600}$ of cells was pelleted and resuspended in lysis buffer (50 mM Tris- $\mathrm{HCl}, \mathrm{pH} 7.5,150 \mathrm{mM} \mathrm{NaCl}, 5 \mathrm{mM}$ EDTA, $1 \mathrm{mM}$ PMSF and PIC) and lysed mechanically by 15 times of $30 \mathrm{~s}$ interval using $0.5 \mathrm{~mm}$ zirconium beads at maximum speed of a vortex mixer. The supernatant was collected by spinning down the lysate $5 \mathrm{~min}$ at $800 \times g$. The clarified lysate was spun down $1 \mathrm{~h}$ at $100,000 \times g$. The pellet was resuspended in $100 \mu \mathrm{ldd} \mathrm{H}_{2} \mathrm{O}$ and sonicated for $30 \mathrm{~min}$ before quantifying total protein using the bicinchoninic acid (BCA) protein quantification assay (SigmaAldrich). A volume corresponding to $0.3 \mathrm{mg}$ of total protein (79) was transferred into glass vials and lyophilized using Virtis Freeze Dryer under vacuum to record dry weight of each sample. For lipid extraction from whole cells, samples were resuspended in $100 \mu \mathrm{ldd} \mathrm{H}_{2} \mathrm{O}$. Afterwards, $300 \mu \mathrm{l}$ of $0.5 \mathrm{~mm}$ zirconium beads and $900 \mu \mathrm{l}$ of chloroform $\left(\mathrm{CHCl}_{3}\right)$ :methanol $(2: 1)$ were added before rigorous agitation of $2 \mathrm{~h}$ at $4^{\circ} \mathrm{C}$. From here, $300 \mu \mathrm{l}$ each of $\mathrm{CHCl}_{3}$ and $\mathrm{ddH}_{2} \mathrm{O}$ were added to the mixture and vortexed $15 \mathrm{~s}$ twice. The vials were centrifuged 6 min at $4,250 \times g$, and the lower organic phase was transferred to a new glass vial. The extraction step was repeated by the addition of $500 \mu \mathrm{l}$ of $\mathrm{CHCl}_{3}$ and further agitation $2 \mathrm{~h}$. Lipid extraction from microsomes was done similarly with scaleddown reagent volumes. Combined extracts were concentrated, resuspended in $50 \mu \mathrm{l}(20 \mu \mathrm{l}$ for microsomal extracts) $\mathrm{CHCl}_{3}$ :methanol (2:1), and spotted on HPTLC Silica gel 60 plates (Merck Millipore) using Linomat 5 (CAMAG). Triacylglycerol (TG) were separated with toluene: $\mathrm{CHCl}_{3}:$ methanol $(85: 15: 5)$ and visualized under long-wave ultraviolet light (320 $\mathrm{nm}$ ) by spraying $0.05 \mathrm{mg} / \mathrm{ml}$ of primuline dye in acetone:water (80:20) onto the dried plates.

Spots corresponding to TG were scraped off the silica plates and transferred into glass vials. A total of $100 \mu \mathrm{l} 1 \mathrm{mM}$ pentadecanoic acid (C15:0) was added to the tubes as internal standard. TGs were hydrolysed and esterified to fatty acid methyl esters (FAME) with $300 \mu \mathrm{l}$ 
of $1.25 \mathrm{M} \mathrm{HCl}$-methanol for $1 \mathrm{~h}$ at $80^{\circ} \mathrm{C}$. FAMEs were extracted three times with $1 \mathrm{ml}$ of hexane. Combined extracts were dried under nitrogen, resuspended in $20 \mu \mathrm{l}$. FAMEs were separated by gas chromatography with a flame ionisation detector (GC-FID; GC-2014, Shimadzu, Kyoto, Japan) using an ULBON HR-SS-10 $50 \mathrm{~m} \times 0.25$ $\mathrm{mm}$ column (Shinwa,Tokyo, Japan). Supelco 37 component FAME mix was used to identify corresponding FAs (Sigma-Aldrich, St Louis, $\mathrm{MO}$ ). Data were normalised using the internal standard C15:0.

\section{Transmission Electron Microscopy}

Samples for transmission electron microscopy (TEM) were prepared as previously described (80). One OD600 unit of early log-phase cells grown at $25^{\circ} \mathrm{C}$ or $37^{\circ} \mathrm{C}$ was collected and prefixed with glutaraldehyde overnight at $4^{\circ} \mathrm{C}$. Post-fixation was performed in the presence of $2 \%$ potassium permanganate for $1 \mathrm{~h}$ at room temperature. After dehydration in ethanol, cells were infiltrated with Spurr's resin and incubated for $24 \mathrm{~h}$ at $60^{\circ} \mathrm{C}$ to allow polymerization. Silvergray sections were prepared using Ultracut UCT (Leica) equipped with a diamond knife and stained with lead citrate. Micrographs were taken using a transmission electron microscope (Joel JEM-1230).

\section{Phospholipid analysis}

Cells were grown to mid-log phase overnight in medium containing $75 \mu \mathrm{M}$ inositol with (+cho) or without (-cho) $1 \mathrm{mM}$ choline in the presence of $10 \mu \mathrm{Ci} / \mathrm{ml}\left[{ }^{32} \mathrm{P}\right]$-orthophosphate. Cells collected by filtration were resuspended in medium with or without inositol or choline, as indicated, and in the presence of $10 \mu \mathrm{Ci} / \mathrm{ml}$ [32 P]orthophosphate. Cells were harvested after $3 \mathrm{~h}$ following the shift or at indicated time point. Labelled lipids were extracted as previously described (81). The individual phospholipid species were resolved by two-dimensional thin layer chromatography. Phospholipids were separated using the solvent system chloroform/ ethanol/water/triethylamine (30:35:7:35) for at least $2 \mathrm{~h}$. Phospholipid identity was based on the mobility of known standards and quantified on a STORM 860 Phosphorlmager (Amersham Biosciences).

\section{Cycloheximide chase assay}

The cycloheximide chase assay was performed as previously described (51). In brief, $6 \mathrm{OD}_{600}$ units of early log phase cells were grown in appropriate selective media. To induce lipid perturbation, $1 \mathrm{mM}$ of choline chloride was added a day prior to harvesting, whereas inositol depletion was performed two hours beforehand. Protein synthesis was inhibited by adding $200 \mu \mathrm{g} / \mathrm{ml}$ cycloheximide. Samples were taken at designated time points and trichloroacetic acid (TCA) was added to a final $10 \%$ volume. Cells were mechanically disrupted with $300 \mu \mathrm{l}$ of $0.5 \mathrm{~mm}$ zirconium beads at $6,500 \mathrm{rpm}$ for $2 \times 30 \mathrm{~s}$ using a tissue homogeniser (Precellys 24, Bertin Instruments). Precipitated proteins were pelleted $10 \mathrm{~min}$ at $21,000 \times \mathrm{g}, 4^{\circ} \mathrm{C}$, and resuspended in $40 \mu \mathrm{l}$ of TCA Resuspension Buffer (100 mM Tris pH 11, 3\% SDS, $1 \mathrm{mM}$ PMSF, PIC). Solubilised proteins were separated by SDS-PAGE, transferred on nitrocellulose membranes. Immunoblotting was performed with appropriate primary antibodies and IRDye-conjugated secondary antibodies. Proteins were visualised using the NIR fluorescence system (Odyssey CLx Imaging System). Values for each time point were normalised using anti-Tub1 as loading controls. Tonal quality was adjusted for representative images through ImageStudio Lite Version 5.2 (LI-COR Biosciences) where appropriate and was followed by quantification. All comparative analyses were done on immunoblots performed in parallel using samples derived from the same experiment. 
Acknowledgements: We are grateful to Dr. Davis Ng for providing reagents. We thank to members of Thibault lab for critical reading of the manuscript.

Conflict of interest: The authors declare that they have no conflicts of interest with the contents of this article.

Author contributions: Conceptualisation: G.T; Methodology: P.J.S., W.S.Y., M.L.G., C.M., S.A.H. and G.T.; Formal Analysis: P.J.S., W.S.Y., and M.L.G.; Investigation: P.J.S., W.S.Y., M.L.G., S.A.J., and C.M.; Resources: P.J.S., W.S.Y., and M.L.G.; Writing - Original Draft: P.J.S. and G.T.; Writing - Review \& Editing: P.J.S., W.A.P., M.L.G., W.A.P., and G.T.; Funding Acquisition: P.J.S., W.A.P., S.A.H., and G.T.; Supervision: G.T. 
bioRxiv preprint doi: https://doi.org/10.1101/2020.04.06.027847; this version posted April 15, 2020. The copyright holder for this preprint (which was not certified by peer review) is the author/funder. All rights reserved. No reuse allowed without permission.

\section{References}

1. Grillitsch, K., Connerth, M., Kofeler, H., Arrey, T. N., Rietschel, B., Wagner, B., Karas, M., and Daum, G. (2011) Lipid particles/droplets of the yeast Saccharomyces cerevisiae revisited: lipidome meets proteome. Biochim Biophys Acta 1811, 1165-1176

2. Nguyen, T. B., Louie, S. M., Daniele, J. R., Tran, Q., Dillin, A., Zoncu, R., Nomura, D. K., and Olzmann, J. A. (2017) DGAT1-Dependent Lipid Droplet Biogenesis Protects Mitochondrial Function during Starvation-Induced Autophagy. Dev Cell 42, 9-21 e25

3. Lee, P., Kim, M. S., Paik, S. M., Choi, S. H., Cho, B. R., and Hahn, J. S. (2013) Rim15-dependent activation of Hsf1 and Msn2/4 transcription factors by direct phosphorylation in Saccharomyces cerevisiae. FEBS Lett 587, 3648-3655

4. Liu, L., Zhang, K., Sandoval, H., Yamamoto, S., Jaiswal, M., Sanz, E., Li, Z., Hui, J., Graham, B. H., Quintana, A., and Bellen, H. J. (2015) Glial lipid droplets and ROS induced by mitochondrial defects promote neurodegeneration. Cell 160, 177-190

5. Fei, W., Wang, H., Fu, X., Bielby, C., and Yang, H. (2009) Conditions of endoplasmic reticulum stress stimulate lipid droplet formation in Saccharomyces cerevisiae. Biochem J 424, 61-67

6. Lee, J. S., Mendez, R., Heng, H. H., Yang, Z. Q., and Zhang, K. (2012) Pharmacological ER stress promotes hepatic lipogenesis and lipid droplet formation. Am J Transl Res 4, 102-113

7. Thibault, G., Shui, G., Kim, W., McAlister, G. C., Ismail, N., Gygi, S. P., Wenk, M. R., and Ng, D. T. (2012) The membrane stress response buffers lethal effects of lipid disequilibrium by reprogramming the protein homeostasis network. Mol Cell 48, 16-27

8. Hou, N. S., Gutschmidt, A., Choi, D. Y., Pather, K., Shi, X., Watts, J. L., Hoppe, T., and Taubert, S. (2014) Activation of the endoplasmic reticulum unfolded protein response by lipid disequilibrium without disturbed proteostasis in vivo. Proc Natl Acad Sci U S A 111, E2271-2280

9. Fun, X. H., and Thibault, G. (2019) Lipid bilayer stress and proteotoxic stress-induced unfolded protein response deploy divergent transcriptional and non-transcriptional programmes. Biochim Biophys Acta Mol Cell Biol Lipids

10. Ho, N., Wu, H., Xu, J., Koh, J. H., Yap, W. S., Goh, W. W. B., Chong, S. C., Taubert, S., and Thibault, G. (2019) ER stress sensor Ire1 deploys a divergent transcriptional program in response to lipid bilayer stress. bioRxiv

11. Lee, A. H., Scapa, E. F., Cohen, D. E., and Glimcher, L. H. (2008) Regulation of hepatic lipogenesis by the transcription factor XBP1. Science 320, 1492-1496

12. Kadereit, B., Kumar, P., Wang, W. J., Miranda, D., Snapp, E. L., Severina, N., Torregroza, I., Evans, T., and Silver, D. L. (2008) Evolutionarily conserved gene family important for fat storage. Proc Natl Acad Sci U S A 105, 94-99

13. Gross, D. A., Snapp, E. L., and Silver, D. L. (2010) Structural insights into triglyceride storage mediated by fat storage-inducing transmembrane (FIT) protein 2. PLoS One 5, e10796

14. Moir, R. D., Gross, D. A., Silver, D. L., and Willis, I. M. (2012) SCS3 and YFT2 link transcription of phospholipid biosynthetic genes to ER stress and the UPR. PLoS Genet 8, e1002890

15. Cai, Y., McClinchie, E., Price, A., Nguyen, T. N., Gidda, S. K., Watt, S. C., Yurchenko, O., Park, S., Sturtevant, D., Mullen, R. T., Dyer, J. M., and Chapman, K. D. (2017) Mouse fat storage-inducing transmembrane protein 2 (FIT2) promotes lipid droplet accumulation in plants. Plant Biotechnol J $15,824-836$

16. Gross, D. A., Zhan, C., and Silver, D. L. (2011) Direct binding of triglyceride to fat storage-inducing transmembrane proteins 1 and 2 is important for lipid droplet formation. Proc Natl Acad Sci U S A 108, 19581-19586

17. Choudhary, V., Ojha, N., Golden, A., and Prinz, W. A. (2015) A conserved family of proteins facilitates nascent lipid droplet budding from the ER. J Cell Bio/ 211, 261-271

18. Nguyen, L. N., Hamari, Z., Kadereit, B., Trofa, D., Agovino, M., Martinez, L. R., Gacser, A., Silver, D. L., and Nosanchuk, J. D. (2011) Candida parapsilosis fat storage-inducing transmembrane (FIT) protein 2 regulates lipid droplet formation and impacts virulence. Microbes Infect 13, 663-672

19. Becuwe, M., Bond, L. M., Mejhert, N., Boland, S., Elliott, S. D., Cicconet, M., Liu, X. N., Graham, M. M., Walther, T. C., and Farese, R. V. (2018) FIT2 is a lipid phosphate phosphatase crucial for endoplasmic reticulum homeostasis. bioRxiv

20. Choudhary, V., Golani, G., Joshi, A. S., Cottier, S., Schneiter, R., Prinz, W. A., and Kozlov, M. M. (2018) Architecture of Lipid Droplets in Endoplasmic Reticulum Is Determined by Phospholipid Intrinsic Curvature. Curr Biol 28, 915-926 e919

21. Hosaka, K., Nikawa, J., Kodaki, T., Ishizu, H., and Yamashita, S. (1994) Cloning and sequence of the SCS3 gene which is required for inositol prototrophy in Saccharomyces cerevisiae. J Biochem 116, 1317-1321 
bioRxiv preprint doi: https://doi.org/10.1101/2020.04.06.027847; this version posted April 15, 2020. The copyright holder for this preprint (which was not certified by peer review) is the author/funder. All rights reserved. No reuse allowed without permission.

22. Hayes, M., Choudhary, V., Ojha, N., Shin, J. J., Han, G. S., Carman, G. M., Loewen, C. J., Prinz, W. A., and Levine, T. (2017) Fat storage-inducing transmembrane (FIT or FITM) proteins are related to lipid phosphatase/phosphotransferase enzymes. Microb Cell 5, 88-103

23. Jonikas, M. C., Collins, S. R., Denic, V., Oh, E., Quan, E. M., Schmid, V., Weibezahn, J., Schwappach, B., Walter, P., Weissman, J. S., and Schuldiner, M. (2009) Comprehensive characterization of genes required for protein folding in the endoplasmic reticulum. Science 323, 1693-1697

24. Travers, K. J., Patil, C. K., Wodicka, L., Lockhart, D. J., Weissman, J. S., and Walter, P. (2000) Functional and genomic analyses reveal an essential coordination between the unfolded protein response and ER-associated degradation. Cell 101, 249-258

25. Cox, J. S., and Walter, P. (1996) A novel mechanism for regulating activity of a transcription factor that controls the unfolded protein response. Cell 87, 391-404

26. Cox, J. S., Chapman, R. E., and Walter, P. (1997) The unfolded protein response coordinates the production of endoplasmic reticulum protein and endoplasmic reticulum membrane. Mol Biol Cell 8, 1805-1814

27. Halbleib, K., Pesek, K., Covino, R., Hofbauer, H. F., Wunnicke, D., Hanelt, I., Hummer, G., and Ernst, R. (2017) Activation of the Unfolded Protein Response by Lipid Bilayer Stress. Mol Cell 67, 673-684 e678

28. Cretenet, G., Le Clech, M., and Gachon, F. (2010) Circadian clock-coordinated $12 \mathrm{Hr}$ period rhythmic activation of the IRE1alpha pathway controls lipid metabolism in mouse liver. Cell Metab 11, 47-57

29. Thibault, G., Ismail, N., and Ng, D. T. (2011) The unfolded protein response supports cellular robustness as a broad-spectrum compensatory pathway. Proc Natl Acad Sci U S A 108, 2059720602

30. Thibault, G., and Ng, D. T. (2011) A screen for mutants requiring activation of the unfolded protein response for viability. Methods Enzymol 491, 199-216

31. Jacquier, N., Choudhary, V., Mari, M., Toulmay, A., Reggiori, F., and Schneiter, R. (2011) Lipid droplets are functionally connected to the endoplasmic reticulum in Saccharomyces cerevisiae. $J$ Cell Sci 124, 2424-2437

32. Henry, S. A., and Patton-Vogt, J. L. (1998) Genetic regulation of phospholipid metabolism: yeast as a model eukaryote. Prog Nucleic Acid Res Mol Biol 61, 133-179

33. Carman, G. M., and Henry, S. A. (1999) Phospholipid biosynthesis in the yeast Saccharomyces cerevisiae and interrelationship with other metabolic processes. Prog Lipid Res 38, 361-399

34. Carman, G. M., and Kersting, M. C. (2004) Phospholipid synthesis in yeast: regulation by phosphorylation. Biochem Cell Biol 82, 62-70

35. Guan, X. L., Souza, C. M., Pichler, H., Dewhurst, G., Schaad, O., Kajiwara, K., Wakabayashi, H., Ivanova, T., Castillon, G. A., Piccolis, M., Abe, F., Loewith, R., Funato, K., Wenk, M. R., and Riezman, H. (2009) Functional interactions between sphingolipids and sterols in biological membranes regulating cell physiology. Mol Biol Cell 20, 2083-2095

36. Liu, M., Huang, C., Polu, S. R., Schneiter, R., and Chang, A. (2012) Regulation of sphingolipid synthesis through Orm1 and Orm2 in yeast. J Cell Sci 125, 2428-2435

37. Snider, J., Kittanakom, S., Damjanovic, D., Curak, J., Wong, V., and Stagljar, I. (2010) Detecting interactions with membrane proteins using a membrane two-hybrid assay in yeast. Nat Protoc 5, 1281-1293

38. Tavassoli, S., Chao, J. T., Young, B. P., Cox, R. C., Prinz, W. A., de Kroon, A. I., and Loewen, C. J. (2013) Plasma membrane--endoplasmic reticulum contact sites regulate phosphatidylcholine synthesis. EMBO Rep 14, 434-440

39. Allen, K. D., Chernova, T. A., Tennant, E. P., Wilkinson, K. D., and Chernoff, Y. O. (2007) Effects of ubiquitin system alterations on the formation and loss of a yeast prion. J Biol Chem 282, 30043013

40. Chiabudini, M., Conz, C., Reckmann, F., and Rospert, S. (2012) Ribosome-associated complex and Ssb are required for translational repression induced by polylysine segments within nascent chains. Mol Cell Biol 32, 4769-4779

41. Ohba, M. (1994) A 70-kDa heat shock cognate protein suppresses the defects caused by a proteasome mutation in Saccharomyces cerevisiae. FEBS Lett 351, 263-266

42. Habeck, G., Ebner, F. A., Shimada-Kreft, H., and Kreft, S. G. (2015) The yeast ERAD-C ubiquitin ligase Doa10 recognizes an intramembrane degron. J Cell Biol 209, 261-273

43. Ravid, T., Kreft, S. G., and Hochstrasser, M. (2006) Membrane and soluble substrates of the Doa10 ubiquitin ligase are degraded by distinct pathways. EMBO J 25, 533-543 
bioRxiv preprint doi: https://doi.org/10.1101/2020.04.06.027847; this version posted April 15, 2020. The copyright holder for this preprint (which was not certified by peer review) is the author/funder. All rights reserved. No reuse allowed without permission.

44. Swanson, R., Locher, M., and Hochstrasser, M. (2001) A conserved ubiquitin ligase of the nuclear envelope/endoplasmic reticulum that functions in both ER-associated and Matalpha2 repressor degradation. Genes Dev 15, 2660-2674

45. Dick, T. P., Nussbaum, A. K., Deeg, M., Heinemeyer, W., Groll, M., Schirle, M., Keilholz, W., Stevanovic, S., Wolf, D. H., Huber, R., Rammensee, H. G., and Schild, H. (1998) Contribution of proteasomal beta-subunits to the cleavage of peptide substrates analyzed with yeast mutants. $J$ Biol Chem 273, 25637-25646

46. Jager, S., Groll, M., Huber, R., Wolf, D. H., and Heinemeyer, W. (1999) Proteasome beta-type subunits: unequal roles of propeptides in core particle maturation and a hierarchy of active site function. J Mol Biol 291, 997-1013

47. Spear, E. D., and Ng, D. T. (2003) Stress tolerance of misfolded carboxypeptidase $Y$ requires maintenance of protein trafficking and degradative pathways. Mol Biol Cell 14, 2756-2767

48. Ruggiano, A., Mora, G., Buxo, L., and Carvalho, P. (2016) Spatial control of lipid droplet proteins by the ERAD ubiquitin ligase Doa10. EMBO J 35, 1644-1655

49. Kory, N., Farese, R. V., Jr., and Walther, T. C. (2016) Targeting Fat: Mechanisms of Protein Localization to Lipid Droplets. Trends Cell Biol 26, 535-546

50. Kanehara, K., Xie, W., and Ng, D. T. (2010) Modularity of the Hrd1 ERAD complex underlies its diverse client range. J Cell Biol 188, 707-716

51. Prasad, R., Kawaguchi, S., and Ng, D. T. (2010) A nucleus-based quality control mechanism for cytosolic proteins. Mol Biol Cell 21, 2117-2127

52. Shyu, P., Jr., Ng, B. S. H., Ho, N., Chaw, R., Seah, Y. L., Marvalim, C., and Thibault, G. (2019) Membrane phospholipid alteration causes chronic ER stress through early degradation of homeostatic ER-resident proteins. Sci Rep 9, 8637

53. Adeyo, O., Horn, P. J., Lee, S., Binns, D. D., Chandrahas, A., Chapman, K. D., and Goodman, J. M. (2011) The yeast lipin orthologue Pah1p is important for biogenesis of lipid droplets. J Cell Biol 192, 1043-1055

54. Cartwright, B. R., Binns, D. D., Hilton, C. L., Han, S., Gao, Q., and Goodman, J. M. (2015) Seipin performs dissectible functions in promoting lipid droplet biogenesis and regulating droplet morphology. Mol Biol Cell 26, 726-739

55. Szymanski, K. M., Binns, D., Bartz, R., Grishin, N. V., Li, W. P., Agarwal, A. K., Garg, A., Anderson, R. G., and Goodman, J. M. (2007) The lipodystrophy protein seipin is found at endoplasmic reticulum lipid droplet junctions and is important for droplet morphology. Proc Natl Acad Sci U S A 104, 20890-20895

56. Henry, S. A., Kohlwein, S. D., and Carman, G. M. (2012) Metabolism and regulation of glycerolipids in the yeast Saccharomyces cerevisiae. Genetics 190, 317-349

57. Klug, L., and Daum, G. (2014) Yeast lipid metabolism at a glance. FEMS Yeast Res 14, $369-388$

58. Natter, K., and Kohlwein, S. D. (2013) Yeast and cancer cells - common principles in lipid metabolism. Biochim Biophys Acta 1831, 314-326

59. Stordeur, C., Puth, K., Saenz, J. P., and Ernst, R. (2014) Crosstalk of lipid and protein homeostasis to maintain membrane function. Biol Chem 395, 313-326

60. van Meer, G., Voelker, D. R., and Feigenson, G. W. (2008) Membrane lipids: where they are and how they behave. Nat Rev Mol Cell Biol 9, 112-124

61. Loewen, C. J., Young, B. P., Tavassoli, S., and Levine, T. P. (2007) Inheritance of cortical ER in yeast is required for normal septin organization. J Cell Biol 179, 467-483

62. Estrada de Martin, P., Du, Y., Novick, P., and Ferro-Novick, S. (2005) lce2p is important for the distribution and structure of the cortical ER network in Saccharomyces cerevisiae. J Cell Sci 118, 65-77

63. Markgraf, D. F., Klemm, R. W., Junker, M., Hannibal-Bach, H. K., Ejsing, C. S., and Rapoport, T. A. (2014) An ER protein functionally couples neutral lipid metabolism on lipid droplets to membrane lipid synthesis in the ER. Cell Rep 6, 44-55

64. Quon, E., Sere, Y. Y., Chauhan, N., Johansen, J., Sullivan, D. P., Dittman, J. S., Rice, W. J., Chan, R. B., Di Paolo, G., Beh, C. T., and Menon, A. K. (2018) Endoplasmic reticulum-plasma membrane contact sites integrate sterol and phospholipid regulation. PLoS Biol 16, e2003864

65. Schuldiner, M., Collins, S. R., Thompson, N. J., Denic, V., Bhamidipati, A., Punna, T., Ihmels, J., Andrews, B., Boone, C., Greenblatt, J. F., Weissman, J. S., and Krogan, N. J. (2005) Exploration of the function and organization of the yeast early secretory pathway through an epistatic miniarray profile. Cell 123, 507-519

66. Selvaraju, K., Rajakumar, S., and Nachiappan, V. (2014) Identification of a phospholipase B encoded by the LPL1 gene in Saccharomyces cerevisiae. Biochim Biophys Acta 1842, 1383-1392 
67. Weisshaar, N., Welsch, H., Guerra-Moreno, A., and Hanna, J. (2017) Phospholipase Lpl1 links lipid droplet function with quality control protein degradation. Mol Biol Cell 28, 716-725

68. To, M., Peterson, C. W., Roberts, M. A., Counihan, J. L., Wu, T. T., Forster, M. S., Nomura, D. K., and Olzmann, J. A. (2017) Lipid disequilibrium disrupts ER proteostasis by impairing ERAD substrate glycan trimming and dislocation. Mol Biol Cell 28, 270-284

69. Surma, M. A., Klose, C., Peng, D., Shales, M., Mrejen, C., Stefanko, A., Braberg, H., Gordon, D. E., Vorkel, D., Ejsing, C. S., Farese, R., Jr., Simons, K., Krogan, N. J., and Ernst, R. (2013) A lipid E-MAP identifies Ubx2 as a critical regulator of lipid saturation and lipid bilayer stress. Mol Cell 51, 519-530

70. Hampton, R. Y., Gardner, R. G., and Rine, J. (1996) Role of $26 \mathrm{~S}$ proteasome and HRD genes in the degradation of 3-hydroxy-3-methylglutaryl-CoA reductase, an integral endoplasmic reticulum membrane protein. Mol Biol Cell 7, 2029-2044

71. Foresti, O., Ruggiano, A., Hannibal-Bach, H. K., Ejsing, C. S., and Carvalho, P. (2013) Sterol homeostasis requires regulated degradation of squalene monooxygenase by the ubiquitin ligase Doa10/Teb4. Elife 2, e00953

72. Wang, C. W., and Lee, S. C. (2012) The ubiquitin-like (UBX)-domain-containing protein Ubx2/Ubxd8 regulates lipid droplet homeostasis. J Cell Sci 125, 2930-2939

73. Ishii, A., Kawai, M., Noda, H., Kato, H., Takeda, K., Asakawa, K., Ichikawa, Y., Sasanami, T., Tanaka, K., and Kimura, Y. (2018) Accelerated invagination of vacuoles as a stress response in chronically heat-stressed yeasts. Sci Rep 8, 2644

74. Olzmann, J. A., Richter, C. M., and Kopito, R. R. (2013) Spatial regulation of UBXD8 and p97/VCP controls ATGL-mediated lipid droplet turnover. Proc Natl Acad Sci U S A 110, 1345-1350

75. Kandasamy, P., Vemula, M., Oh, C. S., Chellappa, R., and Martin, C. E. (2004) Regulation of unsaturated fatty acid biosynthesis in Saccharomyces: the endoplasmic reticulum membrane protein, Mga2p, a transcription activator of the OLE1 gene, regulates the stability of the OLE1 mRNA through exosome-mediated mechanisms. J Biol Chem 279, 36586-36592

76. Shcherbik, N., and Haines, D. S. (2007) Cdc48p(Npl4p/Ufd1p) binds and segregates membraneanchored/tethered complexes via a polyubiquitin signal present on the anchors. Mol Cell 25, 385397

77. Pascual, F., Hsieh, L. S., Soto-Cardalda, A., and Carman, G. M. (2014) Yeast Pah1p phosphatidate phosphatase is regulated by proteasome-mediated degradation. J Biol Chem 289, 9811-9822

78. Hsieh, L. S., Su, W. M., Han, G. S., and Carman, G. M. (2015) Phosphorylation regulates the ubiquitin-independent degradation of yeast Pah1 phosphatidate phosphatase by the $20 \mathrm{~S}$ proteasome. J Biol Chem 290, 11467-11478

79. Klug, L., Tarazona, P., Gruber, C., Grillitsch, K., Gasser, B., Trotzmuller, M., Kofeler, H., Leitner, E., Feussner, I., Mattanovich, D., Altmann, F., and Daum, G. (2014) The lipidome and proteome of microsomes from the methylotrophic yeast Pichia pastoris. Biochim Biophys Acta 1841, 215-226

80. Wright, R. (2000) Transmission electron microscopy of yeast. Microscopy Research and Technique 51, 496-510

81. Gaspar, M. L., Aregullin, M. A., Jesch, S. A., and Henry, S. A. (2006) Inositol induces a profound alteration in the pattern and rate of synthesis and turnover of membrane lipids in Saccharomyces cerevisiae. J Biol Chem 281, 22773-22785 
bioRxiv preprint doi: https://doi.org/10.1101/2020.04.06.027847; this version posted April 15, 2020. The copyright holder for this preprint (which was not certified by peer review) is the author/funder. All rights reserved. No reuse allowed without permission.

\section{FOOTNOTES}

This work was supported by the Nanyang Assistant Professorship programme from the Nanyang Technological University to G.T., the National Research Foundation, Singapore, under its NRF-NSFC joint research grant call (Synthetic Biology, NRF2018NRFNSFC003SB-006) to G.T., the Nanyang Technological University Research Scholarship to P.J.S. (predoctoral fellowship), the NIH grant GM19629 to S.A.H. the Intramural Research Program of the NIH to W.A.P., The National Institute of Diabetes and Digestive and Kidney Diseases (NIDDK) to W.A.P.

The abbreviations used are: 3'-AT, 3'-amino-1,2,4,-triazole; CD4, cluster of differentiation 4; CytoQC, cytosolic protein quality control ; DAG, diacylglycerol; ER, endoplasmic reticulum; ERAD, ERassociated degradation; FIT, fat storage inducing transmembrane; GC-FID, gas chromatography with flame ionization detector; HSR, heat shock response; LBS, lipid bilayer stress; LD, lipid droplet; MAG, monoacylglycerol; MYTH, membrane yeast two hybrid; PA, phosphatidic acid; PC, phosphatidylcholine; PE, phosphatidylethanolamine; PI, phosphatidylinositol; PS, phosphatidylserine; OE, overexpression; ScFIT, S. cerevisiae FIT homologues; SE, steryl ester; SGA, synthetic genetic array; TEM, transmission electron microscopy; TG, triacylglycerol; TLC, thin layer chromatography; Tm, tunicamycin; UPR, unfolded protein response; UPS, ubiquitin-proteasome system; X-gal, 5-bromo-4-chloro-3-indolyl- $\beta$-Dgalactopyranoside. 


\section{FIGURES}

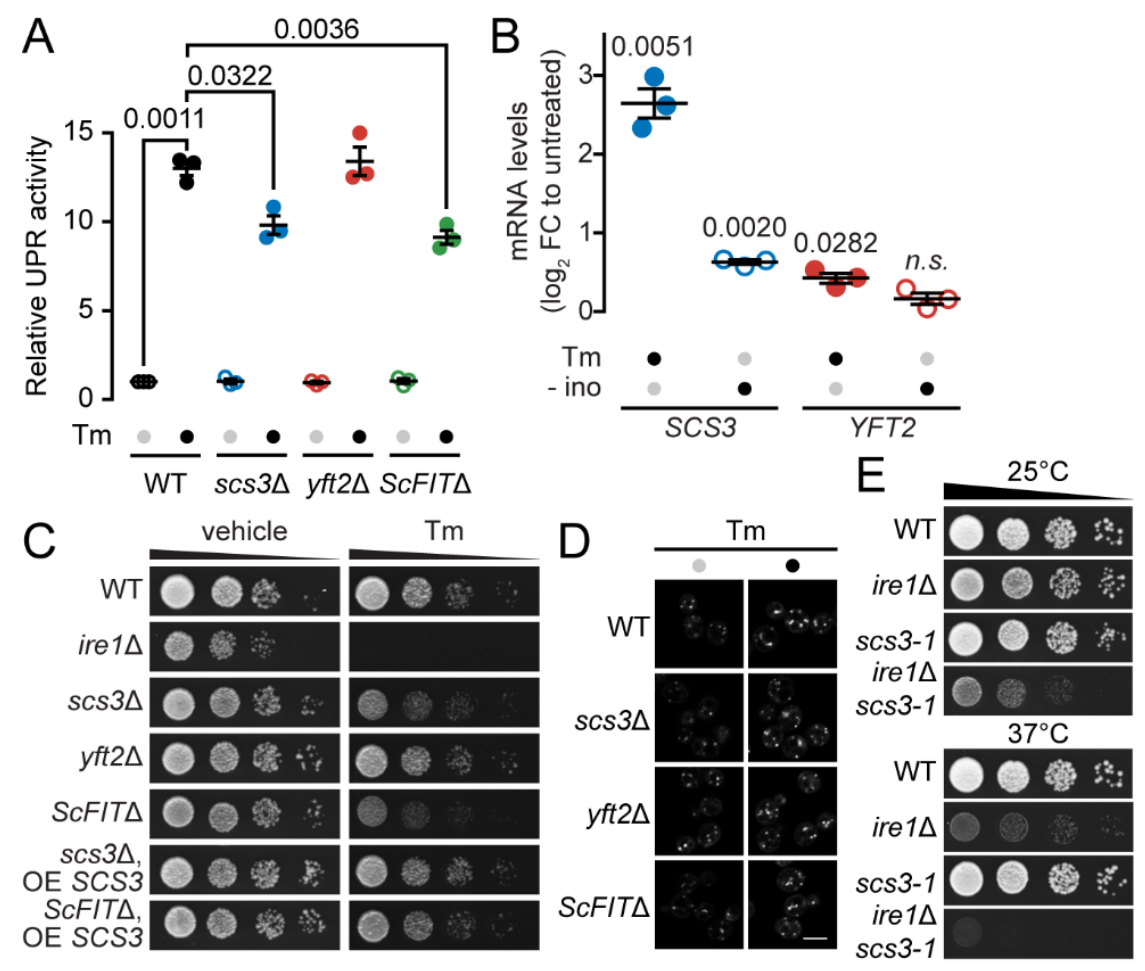

Figure 1. Scs3 is essential for viability in the absence of UPR transducer Ire1. (A) Activation of the UPR was measured by a reporter assay utilizing the expression of the LacZ enzyme under the CYC1 promoter with the UPR element. Cells were either treated with the $\mathrm{N}$-linked glycosylation inhibitor tunicamycin $(\mathrm{Tm})$ or the carrier DMSO for $1 \mathrm{~h}$ prior to harvesting for the assay. (B) qPCR results comparing the mRNA levels of SCS3 and YFT2 if WT cells with $0.25 \mu \mathrm{g} / \mathrm{ml}$ tunicamycin $(\mathrm{Tm})$ or the absence of inositol (- ino), when indicated. (C) ScFIT mutant strains were grown in selective medium prior to dilution and spotting on vehicle or Tm-supplemented media. Culture plates were incubated at $30^{\circ} \mathrm{C}$ until colonies are observed. OE, overexpressed. (D) WT and $\operatorname{scs} 3 \Delta$ mutant cells were treated with $\mathrm{Tm}$ for $1 \mathrm{~h}$ before LD staining with the fluorescent BODIPY 493/503 dye. Scale bar, $2 \mu \mathrm{m}$. Images shown are representative of three independent experiments. (E) Strains in the PER genetic background were grown at $25^{\circ} \mathrm{C}$ in minimal media from which dilutions were prepared and spotted onto plates. Plates were incubated at the specified temperatures until colonies were observed. Data shown is the mean \pm SEM from three independent experiments. Statistical analysis was subjected to paired twotailed Student's t-test. n.s., non-significant. 

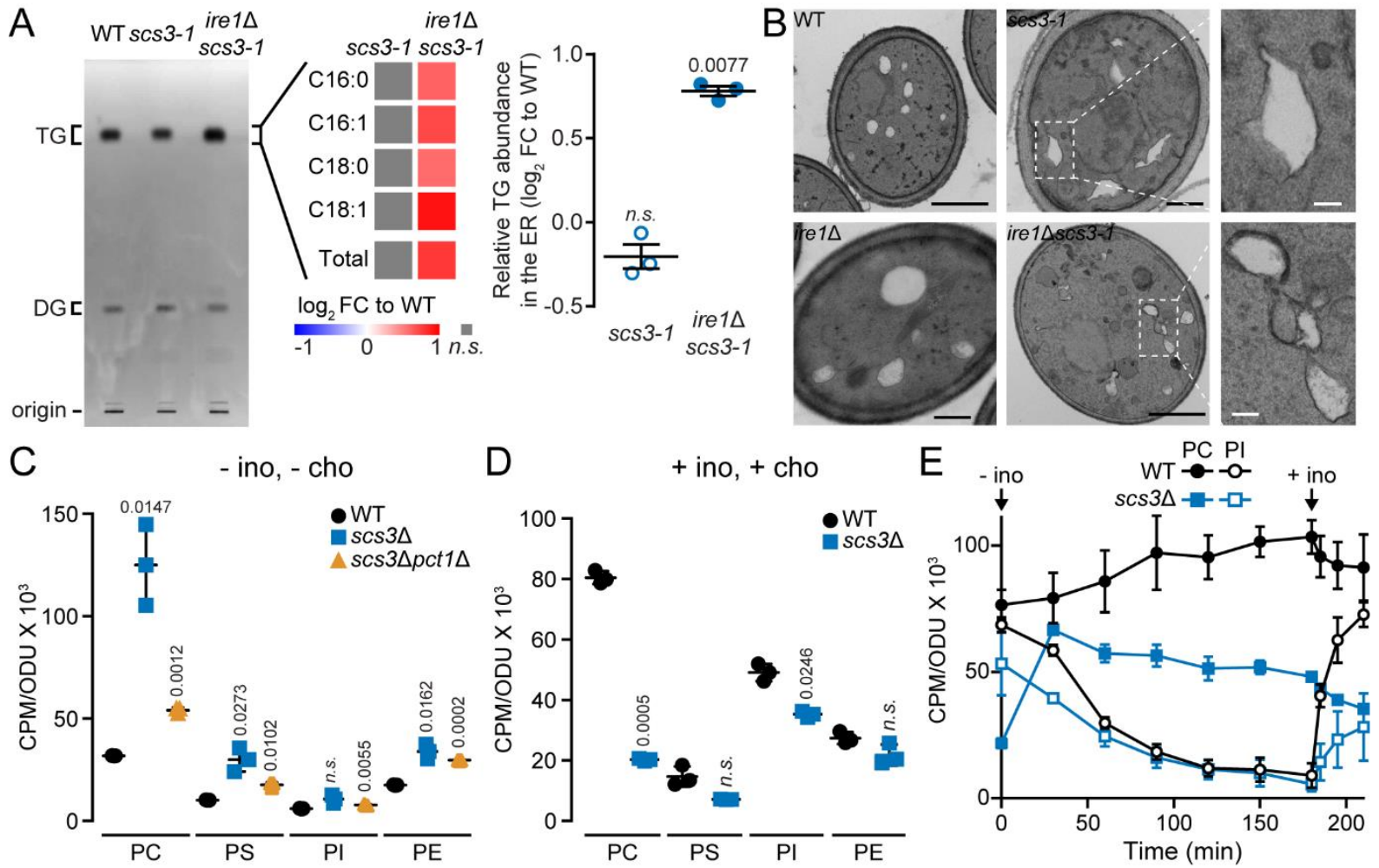

Figure 2. Scs3 is necessary to maintain lipid homeostasis and LD morphology. (A) Strains were grown to log phase at $25^{\circ} \mathrm{C}$ in minimal media, after which the temperature was shifted to $37^{\circ} \mathrm{C}$ for $2 \mathrm{~h}$. Extracted microsomal lipids were separated on TLC plates. TG, triacylglycerol; DG diacylglycerol. Changes in TG acyl chain profiles. All FA species were normalised against WT levels. Relative TG abundance was determined by FAME analysis through GC-FID and normalised against WT. (B) Strains were grown to log phase at $25^{\circ} \mathrm{C}$ in minimal media and shifted to $37^{\circ} \mathrm{C}$ for $2 \mathrm{~h}$ before imaging. Scale bar, $500 \mathrm{~nm}$ (zoomed-in images $100 \mathrm{~nm}$ ). (C) Phospholipid levels of cells grown in media without inositol and choline (- ino, - cho) in the presence of $\left.{ }^{32} \mathrm{P}\right]-$ orthophosphate. Phosphatidylcholine (PC), phosphatidylserine (PS), phosphatidylinositol (PI), and phosphatidylethanolamine (PE) were separated by thin layer chromatography (TLC). (D) Phospholipid levels of cells grown in medial with inositol and choline (+ ino, + cho) treated as in (C). (E) PC and PI levels of cells transferred to media depleted of inositol (- ino) over the course of $3 \mathrm{~h}$ followed by a reintroduction of inositol (+ ino) for a period of $0.5 \mathrm{~h}$. Data shown is the mean \pm SEM from three independent experiments. Statistical analysis was subjected to paired twotailed Student's t-test. n.s., non-significant. 


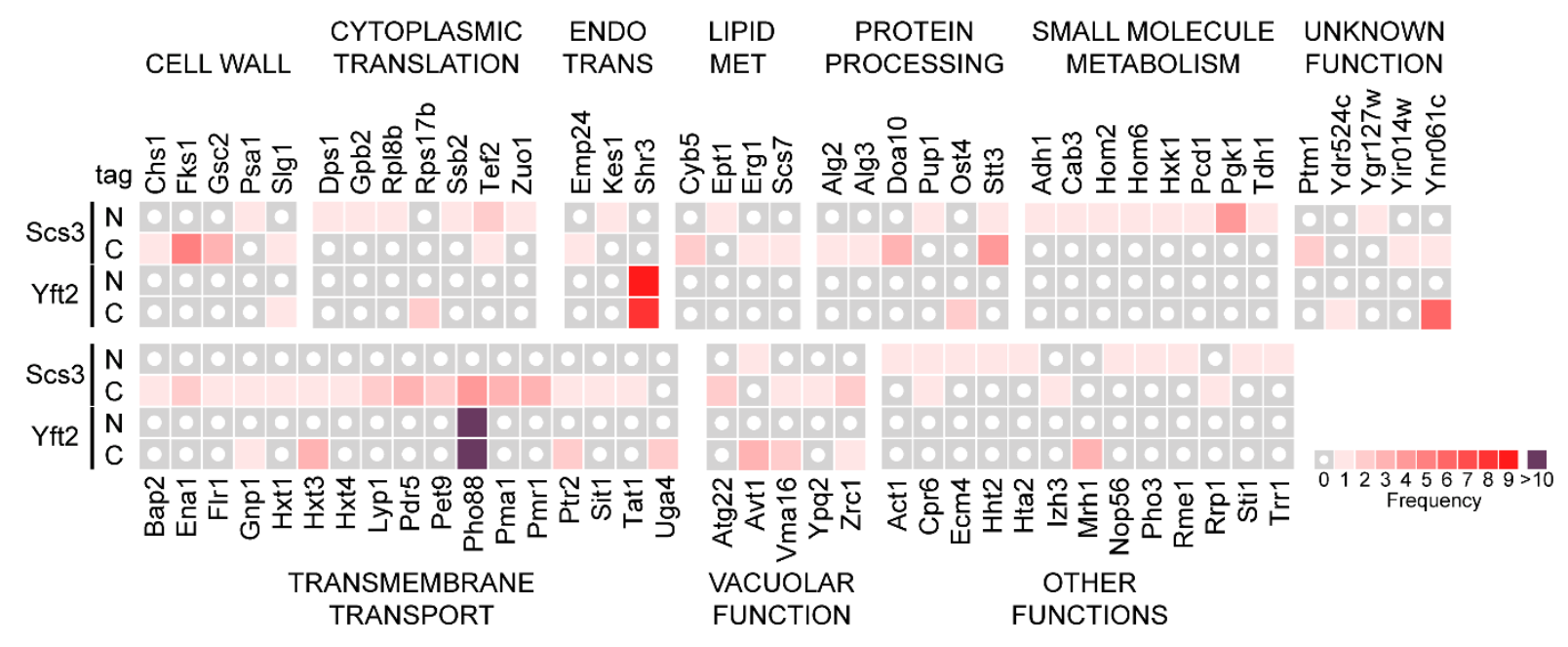

Figure 3. The ScFIT interactome as identified by membrane yeast two-hybrid screening. The frequency by which each unique protein interactor was identified in ScFIT reporter constructs tagged in either $\mathrm{N}$ or C- terminus is represented in a heat map and are grouped according to function.
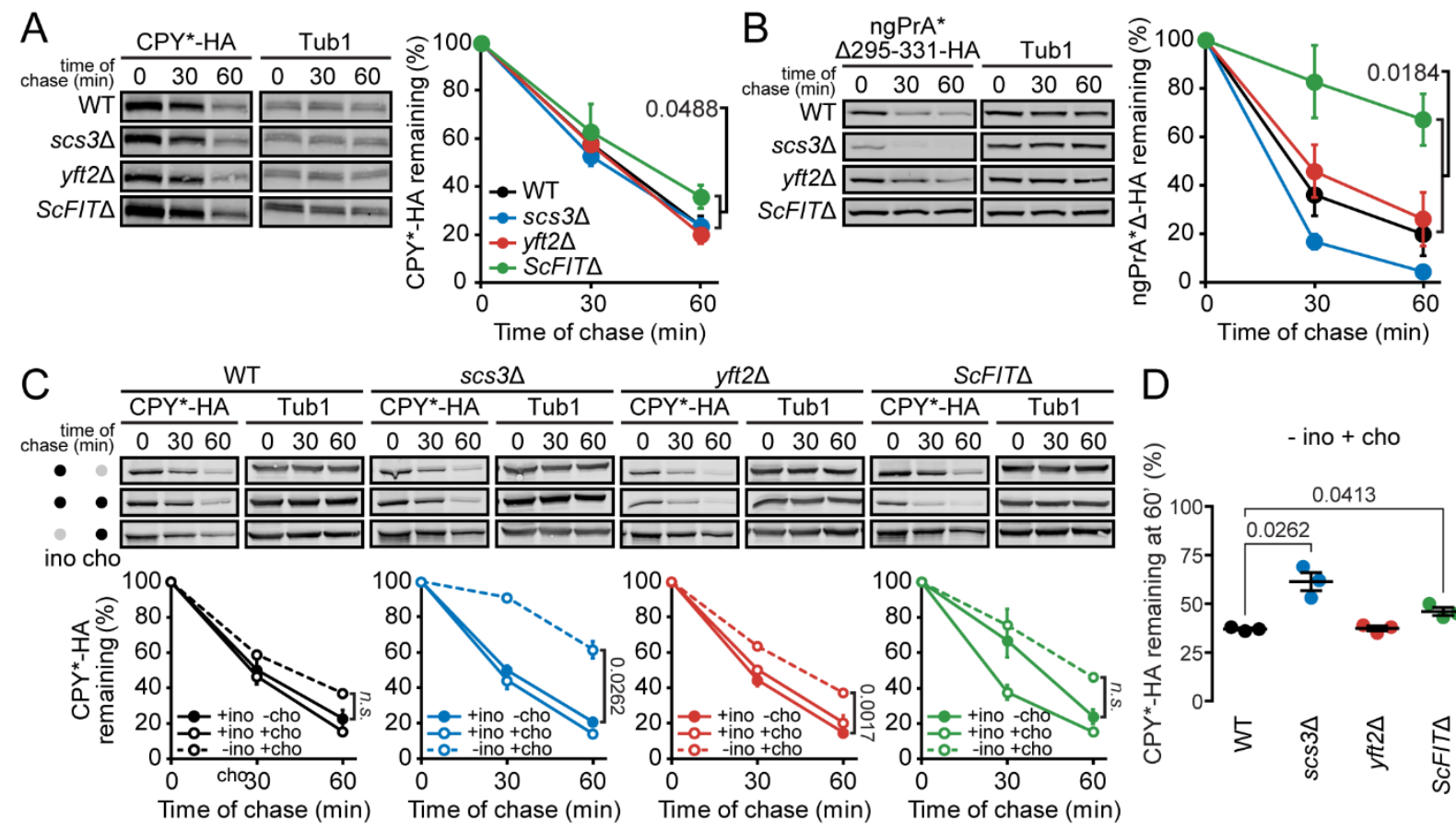

Figure 4. The clearance of ERAD client proteins is impaired in ScFIT mutants. (A-B) Protein levels of the model Hrd1-dependent ERAD substrates, (A) $C^{*} Y^{*}-H A$ and (B) $n g \operatorname{PrA}^{*} \Delta 295-331-H A$, were monitored at 0,30 , and 60 min time points following the attenuation of protein translation with cycloheximide. (C) Strains were treated as in (A) but were grown in the presence of inositol and absence of choline (+ ino, - cho), in the presence of inositol and choline $(+$ ino, + cho), or in the presence of choline and absence of inositol (- ino, + cho). (D) Percentage of CPY*-HA remaining at $60 \mathrm{~min}$ of samples grown in the presence of choline and absence of inositol (- ino, + cho). Data shown are the mean \pm SEM from three independent experiments. Statistical analysis was subjected to paired twotailed Student's t-test. 

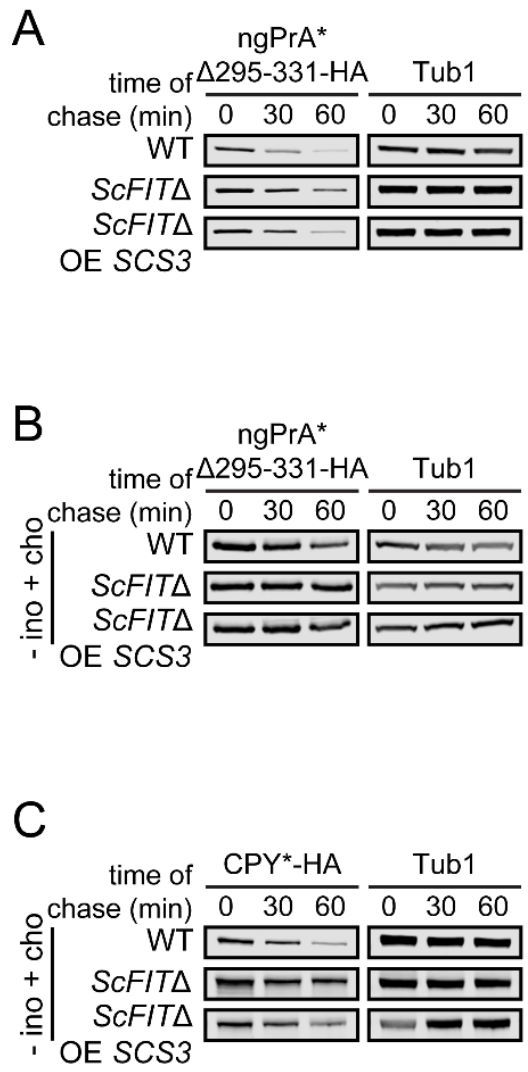
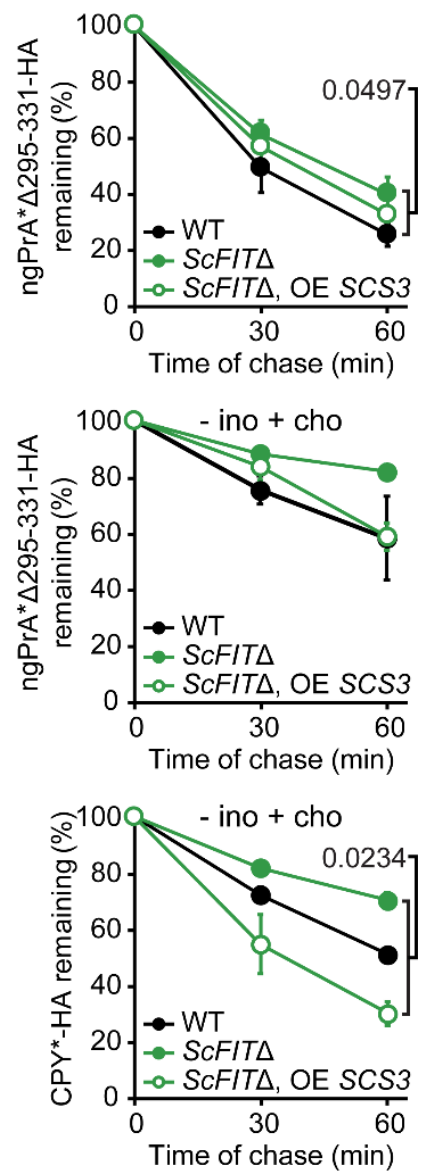

Figure 5. Scs3 is sufficient to rescue proteostatic defect of ScFITA. (A) ngPrA* $\Delta 295-331-H A$ protein levels were monitored at 0,30 , and 60 min time points following the attenuation of protein translation with cycloheximide. OE, overexpressed. (B) $n g \operatorname{PrA}^{*} \Delta 295-331-\mathrm{HA}$ protein levels of cells treated as in (A) but in the absence of inositol (- ino, + cho). (C) CPY*-HA protein levels of cells treated as in (A) but in the absence of inositol (- ino, + cho).

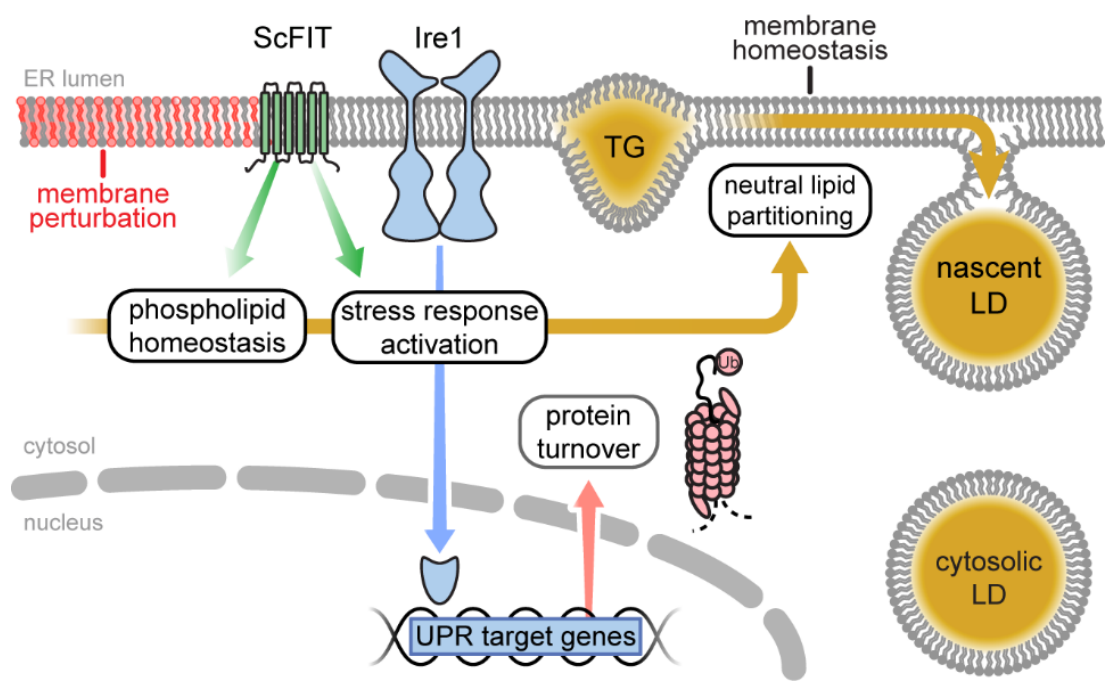

Figure 6. Model for the putative role of ScFIT proteins in coordinating lipid and protein homeostasis. The ScFIT proteins functions in membrane homeostasis by preventing aberrant triacylglycerol (TG) accumulation within the ER, thereby contributing to lipid droplet (LD) maturation. High levels of TG within the ER membrane may impair protein turnover. Alternatively, ScFIT proteins may directly modulate proteostatic pathways, such as the unfolded protein response (UPR) and heat shock response (HSR), to aid in this process with an unknown mechanism. 